\title{
Making a Choice
}

2019

Joan M. Carlson

It is our responsibility as educators to see that our students receive training to meet the present-day challenges facing our clients. The graduate programs in social work are especially suited for training and implementing Screening Brief Intervention and Referral to Treatment (SBIRT) as these programs prepare advanced practitioners to provide care to those with the greatest need and often the least access to mental health and addiction treatment. Schools of Social Work have a strong history of placing advanced clinical MSW interns that focus on diverse populations in behavioral health clinics, primary care clinics, hospitals, substance abuse clinics, schools, residential facilities, family preservation and reunification, child services as well as an essential presence in the VA system. Making a choice to include SBIRT training in our curricula is a viable strategy for enhancing the skills our students will need in practice with strong potential to increase the number of providers while significantly increasing access to behavioral interventions for clients and patients.

Keywords: Evidence-based practice, alcohol, Screening Brief Intervention and Referral to Treatment (SBIRT), MSW curricula

We have come a long way in improving social work curricula to respond to the growing demand of educating our students to the highest standard; however, in my opinion social work programs are not providing adequate preparation for the challenges of present-day social work with the increased prevalence of clients experiencing alcohol and other drug (AOD) disorders. It is especially important to give students not only up-to-date information, but also evidence-based practice (EBP) training so they

This is the author's manuscript of the work published in final edited form as: 
can effectively serve these individuals. Sadly, many of our current social work programs have limited AOD and addiction content in their curricula (Krull et al., 2018). The intent of this endpage is to not only point out the importance of modifying curricula to better prepare students to work with clients experiencing AOD problems, but to advocate for making the choice to include Screening, Brief Intervention, and Referral to Treatment (SBIRT) as part of the curriculum.

I remember my very first day walking into my first-year field placement in my MSW program more than two decades ago. My heart was racing; I felt scared and more importantly ill equipped to face what lay ahead. Other than a generic understanding of alcohol treatment based largely on information about Alcoholics Anonymous meetings from my course content, I was clueless. I had been assigned to a standalone psychiatric hospital to work extensively with in-patient adolescents diagnosed with AOD disorders as well as with adults receiving intensive outpatient treatment for AOD disorders who were often diagnosed with additional mental health disorders. Fate, however, was on my side. I was blessed with an amazing field supervisor who carefully guided my training, all the while exemplifying the values of a professional social worker.

I was like a sponge, attending trainings and taking in new information daily that proved to be essential in the care and treatment of clients and patients. That yearning to educate myself on AOD issues has never ceased. After one semester, my supervisor secured a part-time position for me in the hospital with an emphasis on AOD family group education that lasted for the duration of my MSW studies. It was an extraordinary opportunity to effectively use training and tools to serve family members and patients in a hospital setting.

My first job following the completion of my MSW studies was working as a 2-week temp on a federal grant to explore alcohol prevention programming for middle school youth in the southeastern United States. I ended up staying for more than 14 years. I worked my way up to senior research associate, 
which involved directing a number of randomized clinical controlled trials examining the effectiveness of AOD prevention and intervention programs for middle school, high school, and college students. Again, I had two very engaging supervisors who provided me with multiple opportunities to expand my knowledge base. My on-the-job training from both field placement and prevention research filled gaps in my MSW course work addressing and treating AOD use disorders. The realization that I did not receive much of my AOD knowledge as part of my social work education was somewhat unsettling. I could see that AOD was often comingled with so many issues facing our social work clients. Professionally, I have witnessed many graduates experiencing this same gap in their course work. After working in AOD prevention and intervention research for nearly two decades, I determined it was time to change direction in my professional life; I wanted to be in the classroom. It was not difficult making the choice to obtain a doctorate from Florida State University focused on AOD. My goal was to educate myself further with the intention to help prepare students to meet the plethora of needs associated with AOD disorders.

The fundamental mission of our MSW programs is to prepare students to be state-of-the-art practitioners. Thus, we are letting our students down when we do not stress AOD training, because reduction of the misuse of AOD is at the forefront of global and national health policies. The magnitude and scope of problems related to AOD use demand our immediate attention. The National Association of Social Workers (NASW, 2013) stated, "Social workers are in a unique position to influence the delivery of services by addressing the acute and chronic needs of clients with Substance Use Disorders (SUDs)" (p. 6). NASW (2013) further noted, "By developing and applying evidence-informed approaches that incorporate established interventions and evolving techniques based on emerging research findings, social workers can markedly improve treatment services for clients and their families" (p. 6). Although many social workers are trained in mental health and substance use disorders, a significant number of other social workers without such knowledge provide services to individuals and families where alcohol 
or substance use can be a primary component of presenting problems. It is critical that we provide training for all of our students no matter their area of concentration in academia. SBIRT has proven effective at reducing alcohol consumption (Cherpitel, Moskalewicz, Swiatkiewicz, Ye, \& Bond, 2009) and improving general and mental health (Madras et al., 2009). Implementing SBIRT in practice has also been shown to be economical by benefiting a large number of clients at significant cost savings (Quanbeck, Lang, Enami, \& Brown, 2010).

In the past decade numerous social work programs across the United States have been awarded funding from the Substance Abuse and Mental Health Services Administration (SAMSHA) to design and implement SBIRT within their curricula. These awardees have been afforded opportunities to meet with one another; talk with knowledgeable professionals in the field; have a site visit with expert technical assistance emphasizing sustainability; access to numerous webinars and print materials; and access to an SBIRT consortium within the Council on Social Work Education (CSWE). It should be noted that the CSWE strongly supports this EBP as illustrated by their sponsorship of work over the past year to map SBIRT to core competencies found in the Educational Policy and Accreditation Standards (Lemieux, Carlson, Berger, \& Sacco, 2018). Making the choice to advance and, more important, sustain SBIRT is paramount for social work programs that receive funding to develop and employ this EBP within their curricula. Furthermore, social work values stress that we share our successes and knowledge through a multitude of opportunities that include but are not limited to publications, presentations, webinars, community outreach efforts, and conferences (CSWE, 2015). My institution, Indiana University, received an SBIRT grant that was developed by a consortium of the Schools of Social Work, Nursing and Medicine. Collectively we have worked to integrate SBIRT into curricula and participated in numerous SBIRT community outreach efforts to facilitate educating professionals in SBIRT while offering continuing education units. Our ultimate goal is to integrate SBIRT into Indiana's health care and allied health care 
education systems to improve the health of the large number of adolescents and adults at risk for one or more substance use disorders.

MSW programs prepare advanced practitioners to provide care to those with the greatest need and all too often with the least access to mental health and addiction treatment. Including SBIRT training in the social work curricula has a strong potential to affect and successfully increase behavioral interventions in line with the social work practice principle of client-centered care (NASW, 2008). Our graduates fill gaps in health and allied health care by providing services to those in urban, suburban, and rural areas. Preliminary studies of advanced preparation and education of SBIRT with motivational interviewing (MI) indicates it is beneficial for screening, preventative, and primary mental health care to meet the growing needs of our clients (Carlson et al., 2017).

SBIRT instruction and training provides a framework for addressing AOD use with clients and is readily adaptable to social work education programs. The SBIRT process is brief, the screening is universal, and it most often occurs in a non-substance-abuse treatment setting. Teaching our students how to screen helps to determine the presence of a particular problem; the outcome is normally established by a simple yes-no question. Providing an opportunity to use valid prescreening questions can also ascertain the severity and risk level of clients' AOD use. Screening is a significant step toward effective intervention. We know that early identification and intervention lead to better outcomes for our clients (Puddy \& Wilkins, 2011).

Because SBIRT also uses MI as a supportive skill set, it affords an opportunity for scaffolding SBIRT throughout course work into already established MI programming. $\mathrm{MI}$ is an effective evidence-based approach to facilitate finding personal and compelling reasons for behavioral change while building readiness committing to change. Blending SBIRT content with MI packs a one-two punch. I personally put SBIRT into action in a required foundation course for all MSW students covering assessment in 
mental health and addictions. After completing background and fundamental SBIRT education, students role play with one another using various scenarios to help build their skills in both SBIRT and MI. I have also used SBIRT training in advanced practice classes, again giving students numerous opportunities to practice through role-play scenarios. Students have offered positive feedback indicating that they appreciate the opportunity to practice administering a short screen and conducting a brief interview with immediate feedback from myself and their peers. Numerous no-cost and low-cost materials are readily available online and in print format to assist with training in the classroom, making this a costeffective best practice for inclusion into course work.

MSW graduates work in a variety of settings with diverse populations who might present on any given occasion with AOD issues. It has been widely reported that excessive alcohol use is a serious risk factor for disease, as well as social, behavioral, and economic problems causing a number of short- and longterm harmful consequences that increase the chance of injury and early death (Stahre, Roeber, Kanny, Brewer, \& Zhang, 2014; World Health Organization, 2014). Alcohol misuse has become the fourth leading preventable cause of death in the United States (Stahre et al., 2014). In 2010, the economic burden of excessive alcohol use in the United States was a staggering \$249 billion per year, with the U.S. government covering $\$ 100.7$ billion, or $40.4 \%$ of those costs (Sacks, Gonzales, Bouchery, Tomedi, \& Brewer, 2015). The misuse of prescription drugs along with illicit drug use has also risen significantly in the last decade and our nation is currently plagued by a severe opioid epidemic (Centers for Disease Control and Prevention, 2018). The loss of life is astonishing; more than a half-million individuals succumbed to overdoses from 2000 through 2015. The economic burden is estimated at $\$ 55$ billion annually (Center for Behavioral Health Statistics and Quality, 2015). We owe it to our students to prepare them to meet these challenges.

When integrating EBPs, sustainability of programming is important. I believe that environmental support is essential for integrating as well as sustaining SBIRT. Institutional policies can be established to 
maintain the inclusion of SBIRT in curricula. This includes educating and training faculty. Educating ourselves is a lifelong process. SBIRT curriculum modules can be offered to faculty through on-campus workshops, webinars, and building an online repository of course materials. Designating a faculty champion and a small core team can facilitate the process. Likewise, faculty input helps to support curriculum enhancement and assisting new instructors with training and identifying materials appropriate to their courses.

Social work has long enjoyed a reciprocal relationship with our community partners that often include but are not limited to behavioral health clinics, hospitals, substance abuse clinics, schools, family preservation and reunification agencies, and the Veterans Affairs system. Recognizing the important link between SBIRT training and practice can promote strong partnerships. I believe offering SBIRT training to community partners can enhance strategic communication with stakeholders and the public. We all want the best possible outcomes for our students and clients. AOD misuse has a resounding impact on every life in our society. The tools and resources we choose to give to our students and share with the community will have a profound influence on the future practice of social work.

In summary, it is our responsibility as educators to see that students receive training to meet the present-day challenges that face our clients. Currently there is an identified gap in AOD skills training in many MSW programs. This is especially problematic given the AOD health crises confronting our nation today. SBIRT has proven to be beneficial for hazardous alcohol users (O'Donnell et al., 2014). Although evidence is less robust for illicit drug users (Saitz et al., 2014), the screening segment of SBIRT is efficacious for identifying AOD issues. We must not let our students down; we must address this issue head on. SBIRT is evidence based, provides structure, is client centered, and is readily adaptable. All of these are very important standards in social work education. Making the choice to implement SBIRT training in social work curricula is a viable strategy for enhancing the skills our students will need in practice with strong potential to increase the number of providers while significantly increasing access 
to behavioral interventions for clients and patients. Encouraged by the support of the CSWE, I believe this EBP deserves serious consideration for integration into social work programming. 


\section{References}

Carlson, J., Agley, J., Gassman, R., McNelis, A., Schwindt, R., Vannerson, J., ... Khaja, K. (2017). Effects and durability of an SBIRT training curriculum for first year MSW students. Journal of Social Work Practice in the Addictions, 17(1-2), 135-149.

doi:10.1080/1533256X.2017.1304946

Center for Behavioral Health Statistics and Quality. (2015). Behavioral health trends in the United States: Results from the 2014 national survey on drug use and health (HHS Publication No. SMA 15-4927, NSDUH Series H-50). Retrieved from https://www.samhsa.gov/data/sites/default/files/NSDUH-FRR1-2014/NSDUHFRR1-2014.pdf Centers for Disease Control and Prevention. (2018). Overdose deaths involving opioids, cocaine and psychostimulatns United States, 2015-2016. Retrieved from

https://www.cdc.gov/opioids/strategy.html

Cherpitel, C. J., Moskalewicz, J., Swiatkiewicz, G., Ye, Y., \& Bond, J. (2009). Screening, Brief Intervention, and Referral to Treatment (SBIRT) in a Polish emergency department: Threemonth outcomes of a randomized, controlled clinical trial. Journal of Studies on Alcohol and Drugs, 70, 982-990. doi:10.15288/jsad.2009.70.982

Council on Social Work Education. 2015. Educational Policies and Accreditation Standards. Available online: https://www.cswe.org/Accreditation/Standards-and-Policies/2015-EPAS (accessed on 2018, October 31).tandards. Retrieved from Krull, I., Salas-Wright, C., Amodeo, M., Hall, T., Alford, D., \& Lundgren, L. (2018). Integrating alcohol and other drug content in the social work curriculum: Practices and perceived barriers. Journal of Social Work Practice in the Addictions, 18(1), 30-48.

doi:10.1080/1533256X.2017.1412978 
Lemieux, C., Carlson, J., Berger, L., \& Sacco, P. (2018, March). Mapping SBIRT to the educational policy and accreditation standards. [Webinar] In CSWE SBIRT Webinar Series. Retrieved from http://eventcenter.commpartners.com/se/Meetings/Playback.aspx?meeting.id=584922 Madras, B. K., Compton, W. M., Avula, D., Stegbauer, T., Stein, J. B., \& Clark, H. W. (2009). Screening, brief interventions, referral to treatment (SBIRT) for illicit drug and alcohol use at multiple healthcare sites: Comparison at intake and 6 months later. Drug and Alcohol Dependence, 99(1-3), 280-295. doi:10.1016/j.drugalcdep.2008.08.003 National Association of Social Workers. (2008, October 31). Ethical standards to the code of ethics. Retrieved from https://www.socialworkers.org/About/Ethics/Code-of-Ethics/Code-of$\underline{\text { Ethics-English }}$

National Association of Social Workers. (2013). NASW standards for social work practice with clients with substance use disorders. Washington, DC: Author.

O’Donnell, A., Anderson, P., Newbury-Birch, D., Schulte, B., Schmidt, C., \& Kaner, E. (2014). The impact of brief alcohol interventions in primary healthcare: A systematic review of reviews. Alcohol and Alcoholism, 49(1), 66-78. doi:10.1093/alcalc/agt170

Puddy, R. W., \& Wilkins, N. (2011). Understanding evidence Part 1: Best available research evidence A guide to the continuum of evidence of effectiveness. Atlanta, GA: Centers for Disease Control and Prevention.

Quanbeck, A., Lang, K., Enami, K., \& Brown, R. L. (2010). A cost-Benefit analysis of Wisconsin's screening, brief interven tion, and referral to treatment program: Adding the employer's perspective. Wisconsin Medical Journal, 109(1), 9-14. 
Sacks, J., Gonzales, K., Bouchery, E., Tomedi, L., \& Brewer, R. (2015). 2010 national and state costs of excessive alcohol consumption. American Journal of Preventive Medicine, 49(5), e73e79. doi:10.1016/j.amepre.2015.05.031

Saitz, R., Palfai, T. P. A., Cheng, D. M., Alford, D. P., Bernstein, J. A., Lloyd-Travaglini, C. A., Meli, S. M., Chaisson, C. E., \& Samet, J.H. (2014). Screening and brief intervention for drug use in primary care: The ASPIRE randomized clinical trial. Journal of the American Medical Association, 312(5), 502-513. doi:10.1001/jama.2014.7862

Stahre, M., Roeber, J., Kanny, D., Brewer, R. D., \& Zhang, X. (2014). Contribution of excessive alcohol consumption to deaths and years of potential life lost in the United States. Preventing Chronic Disease, 11, E109. doi:10.5888/pcd11.130272

World Health Organization. (2014). Global status report on alcohol and health 2014. Retrieved from

http://www.who.int/substance_abuse/publications/global_alcohol_report/msb_gsr_2014_1.pdf?u $\underline{\mathrm{a}+1}$ 